\title{
The influence of stereochemistry on the antioxidant properties of catechin epimers
}

\author{
Małgorzata Muzolf-Panek • Anna Gliszczyńska-Świgło • \\ Henryk Szymusiak $\cdot$ Bożena Tyrakowska
}

Received: 19 July 2012/Revised: 4 September 2012/Accepted: 5 September 2012/Published online: 25 September 2012

(C) The Author(s) 2012. This article is published with open access at Springerlink.com

\begin{abstract}
The influence of stereochemistry on the radical scavenging activity of catechins was investigated by studying the effect of $\mathrm{pH}$ on the antioxidant properties of catechin epimers. The difference in the $\mathrm{pH}$-dependent Trolox equivalent antioxidant capacity (TEAC) profiles was observed only in case of gallocatechin gallate (GCG) and epigallocatechin gallate (EGCG), indicating the influence of steric structure on the TEAC antioxidant activity of these galloyl moiety-containing catechins. Based on comparison of the $\mathrm{pH}$-dependent TEAC values to theoretically calculated parameters, including homolytic $\mathrm{OH}$ bond dissociation energy and ionization potential (IP) as well as theoretically predicted structures of the most stable monoanions of GCG and EGCG, it was concluded that due to steric hindrance in GCG molecule, the IP value of GCG monoanion increases reflecting lower radical scavenging capacity of GCG in comparison with EGCG. It results in the difference in the $\mathrm{pH}$-dependent TEAC profiles of these two catechin epimers at $\mathrm{pH}$ above 3.5. This effect does not occur for other pairs of catechin epimers of this study.
\end{abstract}

Keywords Catechin epimers - Stereochemistry $\cdot$ Radical scavenging activity $\cdot \mathrm{pH} \cdot$ Ionization potential $\cdot$ Bond dissociation energy

M. Muzolf-Panek ( $₫)$

Department of Food Quality Management, Faculty of Food Science and Nutrition, Poznań University of Life Science, Wojska Polskiego 31, 60-624 Poznań, Poland e-mail: mpanek@up.poznan.pl

A. Gliszczyńska-Świgło · H. Szymusiak · B. Tyrakowska Faculty of Commodity Science, The Poznań University of Economics, al. Niepodległości 10, 61-875 Poznań, Poland

\section{Introduction}

Catechins (flavan-3-ols) are very important components of human diet. It is estimated that the average daily catechin consumption amounts to $158.4 \mathrm{mg}$ in the United States what constitutes about $83.5 \%$ of the total flavonoid intake $[1,2]$. The main sources of catechins are green tea $(800 \mathrm{mg} / \mathrm{l})$, chocolate $(600 \mathrm{mg} / \mathrm{l})$, red wine $(300 \mathrm{mg} / \mathrm{l})$, and fruits: apricots or cherry $(250 \mathrm{mg} / \mathrm{kg}$ fresh weight $)$ [3]. Catechins are also widespread in vegetables like broad bean and plant-derived products such as wine [1]. In food, they are present as mono-, oligo-, or polymers at the level ranging from 10 to $250 \mathrm{mg} / \mathrm{kg}$ in fruits, $610 \mathrm{mg} / \mathrm{kg}$ in dark chocolate to $850-2,200 \mathrm{mg} / \mathrm{l}$ in green tea infusion $[1,4,5]$. A relatively high level of catechins in the human diet is often correlated with reduced risk of common chronic diseases such as cancer or cardiovascular disease [6-9]. Beneficial health effects of catechins are mainly ascribed to their antioxidant activity $[8,9]$.

Among all catechins present in food, catechin (C), epicatechin (EC), epigallocatechin (EGC), epicatechin gallate (ECG), and epigallocatechin gallate (EGCG) are the most abundant (Fig. 1). However, after food processing (e.g., brewing green tea or roasting of cocoa beans) catechins could undergo conversion to suitable epimers, for example, epigallocatechin (ECG) to gallocatechin (GC) and EGCG to gallocatechin gallate (GCG) [10]. It was previously reported that stereochemistry could influence the radical scavenging activity of catechins [11]. However, Nanjo et al. [12] observed no significant differences between the radical scavenging activities of catechin epimers; thus, the authors concluded that the scavenging potentials of catechins were not dependent on their steric structures. Similar conclusion was reported by others [13]. As far, the results of these studies give the inconclusive data on the effect of 
Fig. 1 Structure of the catechins of the present study<smiles>Oc1cc(O)c2c(c1)OC(c1ccc(O)c(O)c1)C(O)C2</smiles>

(+)-catechin (C)<smiles>Oc1cc(O)c2c(c1)OC(c1cc(O)c(O)c(O)c1)[C@H](O)C2</smiles>

(-)-gallocatechin (GC)<smiles>O=C(O[C@H]1Cc2c(O)cc(O)cc2OC1c1cc(O)c(O)c(O)c1)c1cc(O)c(O)c(O)c1</smiles>

(-)-gallocatechin gallate (GCG)<smiles>Oc1cc(O)c2c(c1)O[C@H](c1ccc(O)c(O)c1)[C@H](O)C2</smiles>

(-)-epicatechin (EC)<smiles>Oc1cc(O)c2c(c1)O[C@H](c1cc(O)c(O)c(O)c1)[C@H](O)C2</smiles>

(-)-epigallocatechin (EGC)<smiles>O=C(O[C@@H]1Cc2c(O)cc(O)cc2O[C@H]1c1cc(O)c(O)c(O)c1)c1cc(O)c(O)c(O)c1</smiles>

(-)-epigallocatechin gallate (EGCG) stereochemistry on the radical scavenging properties of catechin epimers.

It was recently reported that the radical scavenging activity of green tea catechins increases with increasing $\mathrm{pH}$ of the medium and that the increase results from the increased electron-donating ability of catechins upon deprotonation [14]. However, these studies did not focus on the pH-dependent antioxidant activity of catechin epimers. The influence of $\mathrm{pH}$ on the antioxidant activity of catechin epimers is especially of interest because the $\mathrm{pH}$ of different human body fluids and tissues varies widely from $\mathrm{pH} 1$ in the stomach to $\mathrm{pH} 8.6$ in the pancreas $[15,16]$. The $\mathrm{pH}$ of food products, in which catechins could play antioxidant role, also shows significant variations.

Therefore, the aim of the present study was to investigate the effect of $\mathrm{pH}$ on the Trolox equivalent antioxidant capacity (TEAC) of three pairs of catechin epimers, namely catechin (C) and epicatechin (EC), gallocatechin (GC) and epigallocatechin (EGC), as well as gallocatechin gallate (GCG) and epigallocatechin gallate (EGCG). This was done in order to obtain better insight into the influence of stereochemistry on the radical scavenging activity of catechins. Experimental data for radical scavenging activities (TEAC values) and $\mathrm{OH}$ deprotonation (pKa values) were compared to the theoretically calculated parameters for $\mathrm{OH}$ deprotonation, reflected by the calculated deprotonation energy (DE), for hydrogen atom abstraction, reflected by the calculated bond dissociation energy (BDE), and for electron donation ability, reflected by the calculated ionization potential (IP). There are no literature experimental data on the possible influence of stereochemistry on $\mathrm{pH}$ dependent TEAC antioxidant activity of catechin epimers.

\section{Materials and methods}

\section{Chemicals}

$(+)$-Catechin hydrate, (-)-epicatechin, (-)-gallocatechin, (-)-epigallocatechin, (-)-gallocatechin gallate, (-)-epigallocatechin gallate from green tea, methyl gallate, 
6-hydroxy-2,5,7,8-tetramethylchroman-2-carboxylic acid (Trolox), and microperoxidase-8 (MP8) were purchased from Sigma-Aldrich (Steinheim, Germany). 2,2'-Azinobis (3-ethylbenzothiozoline-6-sulfonic acid) diammonium salt (ABTS) was obtained from Roche (Mannheim, Germany). Hydrogen peroxide (30 \%) was purchased from Merck (Darmstadt, Germany).

\section{TEAC assay}

The TEAC assay is based on the ability of the antioxidant to scavenge the blue-green-colored $\mathrm{ABTS}^{+}{ }^{+}$radical cation relative to the $\mathrm{ABTS}^{+}$scavenging ability of the watersoluble vitamin E analogue, Trolox [17]. The antioxidant activity of catechins and their epimers was measured by the modified TEAC assay performed essentially as described previously [17], with some modifications [18]. The major advantage of the modified TEAC assay is that it permits studying the antioxidant activity over a wide $\mathrm{pH}$ range (2-9.5)

In the present study, microperoxidase-8 (MP8) instead of metmyoglobin was used to generate the $\mathrm{ABTS}^{+}$in phosphate-buffered saline (PBS) $\mathrm{pH}$ 7.4. MP8 (final concentration of $0.2 \mu \mathrm{M}$ ) and ABTS (final concentration of $3.0 \mathrm{mM}$ ) in PBS were mixed, and the reaction was initiated by the addition of hydrogen peroxide (final concentration of $0.1 \mathrm{mM}$ ) [18].

ABTS was incubated with $\mathrm{MP} 8 / \mathrm{H}_{2} \mathrm{O}_{2}$ for an hour in a water bath at $30{ }^{\circ} \mathrm{C}$. The $\mathrm{ABTS}^{+}$solution thus obtained was diluted to $1: 1(\mathrm{v} / \mathrm{v})$ using $0.2 \mathrm{M}$ potassium phosphate buffers of various $\mathrm{pH}$ values to give $\mathrm{ABTS}^{+}{ }^{+}$solutions at $\mathrm{pH}$ values varying between 2 and 9.5. The absorption of the $\mathrm{ABTS}^{+}$solutions was about 0.6. The $\mathrm{ABTS}^{+}$solutions thus obtained were used for determination of the TEAC values. During the TEAC assay measurements, the antioxidants (Trolox or catechins) were added as $1 \%$ $(\mathrm{v} / \mathrm{v})$ of a 100 times concentrated stock solution in ethanol to give the final concentration required. The decrease in absorption caused by the antioxidant compound, measured at $6 \mathrm{~min}$, is reflecting the $\mathrm{ABTS}^{+}$radical scavenging capacity and was plotted against the concentration of the antioxidant. The linear correlation obtained for the plot of the absorbance at $734 \mathrm{~nm}$ versus the increasing concentrations of catechins allows the assumption that the decrease in absorbance reflects especially the reaction between the $\mathrm{ABTS}^{+}$radical cation and the antioxidant, and it is not significantly affected by possible side reactions. The TEAC value represents the ratio of the slope of the plot for scavenging of $\mathrm{ABTS}^{+}$by the antioxidant under investigation to the slope of the plot for $\mathrm{ABTS}^{+}$ scavenging by Trolox, used as an antioxidant standard [17]. The TEAC value is expressed in millimolar concentrations (mM) according to the definition of the TEAC value introduced by Miller et al. [17]. The TEAC value is defined as the concentration of a Trolox solution with equivalent antioxidant potential to a $1 \mathrm{mM}$ concentration of the compound under investigation [17]. The TEAC antioxidant activity of Trolox used in this study as a reference compound was unaffected over the whole $\mathrm{pH}$ range tested and accounted for TEAC $=1$ [18-20].

Solubility of gallocatechin (GC) and gallocatechin gallate (GCG)

Solubility of GC and GCG was checked by absorbance measurements at $270 \mathrm{~nm}$. GC and GCG (final concentrations from 0 to $100 \mu \mathrm{M}$ ) were dissolved in buffer of appropriate $\mathrm{pH}$ (7.4 and 8.5). The linear correlation obtained for the plot of the increasing concentrations of catechins to the absorbance at $270 \mathrm{~nm}$ allows the assumption that the increase in absorbance reflects good solubility of catechins.

Determination of gallocatechin (GC), epigallocatechin (EGC), and gallocatechin gallate (GCG) stability using HPLC

GC, EGC, and GCG (final concentration of $20 \mu \mathrm{M}$ ) were dissolved in buffer of appropriate $\mathrm{pH}$ (7.4 and 8.5) and immediately analyzed at room temperature using highperformance liquid chromatography (HPLC) $(t=0 \mathrm{~min})$. GC, EGC, or GCG solutions of $\mathrm{pH} 7.4$ and 8.5 were also analyzed after 6 min (time needed to perform the TEAC assay). A Waters 600 high-performance liquid chromatograph (Waters, Millford, Ma, USA) equipped with Symmetry $\mathrm{C}_{18}$ column $(150 \mathrm{~mm} \times 3.9 \mathrm{~mm}, 5 \mu \mathrm{m})$ fitted with $\mu$ Bondapak $\mathrm{C}_{18}$ cartridge guard column (Waters, Millford, Ma, USA) was used. A gradient of mobile phase, acetonitrile (solvent $\mathrm{A}$ ) and $0.1 \%$ trifluoroacetic acid (solvent B), was developed and used according to the following gradient: linear increment from $10 \% \mathrm{~A}$ to $35 \% \mathrm{~A}$ during 20 min followed by a linear increase up to $100 \% \mathrm{~A}$ in the next $1 \mathrm{~min}$, which was kept for $1 \mathrm{~min}$ and then returned to the initial conditions within next $10 \mathrm{~min}$. Flow rate was $1 \mathrm{ml} / \mathrm{min}$. Injection volume was $20 \mu \mathrm{l}$. The eluate was detected at $270 \mathrm{~nm}$ using a Waters 996 photodiode-array detector. Degradation of GC, EGC, and GCG after 6 min was expressed as a percentage of appropriate catechin peak area at $t=0 \mathrm{~min}$.

\section{Determination of $\mathrm{pKa}$}

The pKa values of GCG and GC were determined from their absorption spectra as a function of $\mathrm{pH}$ as described by Sauerwald et al. [21]. 
Quantum mechanical calculations

The geometries of catechins and their epimers were fully optimized with the B3LYP hybrid density functional theory (DFT) by using a 6-31G(d,p) basis set as implemented in the Gaussian 98 computational package. Single-point energies were then evaluated by using a higher $6-311+\mathrm{G}(\mathrm{d}, \mathrm{p})$ basis set. The calculated deprotonation energies (DE), IP, and BDEs were not corrected for zeropoint energy and other thermal contributions assuming a negligible error and thus considerably saving computer time, especially in the case of larger molecules like GCG and EGCG.

The DE values were calculated as the electronic energy of the deprotonated molecule minus the electronic energy of the neutral parent molecule. The BDE for homolytic $\mathrm{OH}$ bond cleavage in the neutral molecule $(\mathrm{BDE}(\mathrm{N}))$ was calculated as the electronic energy of the radical resulting from the hydrogen atom abstraction minus the electronic energy of the neutral parent molecule. The IP for the neutral molecule (IP(N)) was calculated as the electronic energy of the radical cation resulting from the electron abstraction minus the electronic energy of the neutral parent molecule.

Similarly, the BDE for homolytic $\mathrm{OH}$ bond cleavage in the deprotonated, monoanionic molecule $(\mathrm{BDE}(\mathrm{A}))$ was calculated as the electronic energy of the radical formed by hydrogen atom abstraction from the most stable phenoxylate monoanion minus the electronic energy of this most stable monoanion molecule. The IP of the most stable monoanion (IP(A)) was calculated as the electronic energy of the phenoxy radical formed by electron abstraction from the most stable phenoxylate monoanion minus the electronic energy of this parent most stable monoanion. In this paper, only the results related to the most stable phenoxylate monoanions and phenoxy radicals are given. No solvent effects are included in the calculations.

\section{Results and discussion}

Catechin epimers are good scavengers of free radicals such as peroxyl radicals, singlet oxygen, peroxynitrate, and hypochlorous acid [22]. The antioxidant action of catechin epimers was also observed in various in vitro assays in water and lipid systems [12, 23-25].

Table 1 presents the TEAC values at $\mathrm{pH} 7.4$ for the catechin epimers under study including $\mathrm{C}$ and EC, GC and EGC, and GCG and EGCG. For comparison, Table 1 also contains literature data on the antioxidant activity of the catechin epimers determined by the TEAC assay at $\mathrm{pH} 7.4$ [23], DPPH assay [12], LPO (lipid peroxidation) assay [24], and SRSA (superoxide radical scavenging activity) assay [25]. Based on the experimental data shown in Table 1, it could be concluded that the antioxidant activity of catechin epimers, C and EC as well as GC and EGC,

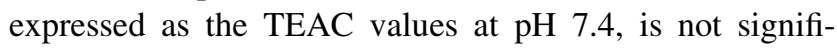
cantly different in contrast to the antioxidant activity of GCG and EGCG. The difference between the TEAC values of C and EC reported by Rice-Evans et al. [23] is also not significantly high. There are also no statistically significant differences observed for all catechin epimers tested using DPPH [12] and SRSA assays [25]. However, in LPO assay, it was shown that the antioxidant activities of epimers, C and EC as well as GC and EGC, vary significantly [24]. Since the lipophilicity and oxidation potential values for corresponding catechin epimers do not differ, Yang et al. [24] suggested that the differences in the antioxidant activities could be caused by the differences in steric structures of the compounds.

In the present study, the influence of stereochemistry on the antioxidant activity of catechins was studied by comparing the $\mathrm{pH}$-dependent TEAC profiles of catechin epimers. The antioxidant action of catechin epimers was observed not only in in vitro studies but also in ex vivo and in vivo studies [12, 26-28]. Since $\mathrm{pH}$ range of different human body fluids and tissues varies widely, from $\mathrm{pH}$

Table 1 Antioxidant activity of catechin epimers in various assays

\begin{tabular}{|c|c|c|c|c|c|}
\hline Catechins & TEAC $_{\text {exp. }}(\mathrm{pH} 7.4)$ & TEAC $^{\mathrm{a}}(\mathrm{pH}$ 7.4) & $\mathrm{DPPH}^{\mathrm{b}} \mathrm{SC}_{50}(\mu \mathrm{M})$ & $\mathrm{LPO}^{\mathrm{c}} \mathrm{IC}_{50}(\mu \mathrm{M})$ & $\mathrm{SRSA}^{\mathrm{e}} \mathrm{IC}_{50}(\mathrm{mM})$ \\
\hline Catechin $(\mathrm{C})$ & $3.34 *$ & 2.40 & 2.9 & 51.0 & 6.08 \\
\hline Epicatechin (EC) & $3.58 *$ & 2.50 & 3.0 & 30.0 & 5.75 \\
\hline Gallocatechin (GC) & $3.43 * *$ & - & 2.1 & 29.3 & 0.71 \\
\hline Epigallocatechin (EGC) & $3.61^{\mathrm{d} * *}$ & 3.82 & 1.8 & 16.0 & 0.75 \\
\hline Gallocatechin gallate (GCG) & 4.80 & - & 1.1 & 13.0 & 0.39 \\
\hline Epigallocatechin gallate (EGCG) & $6.01^{\mathrm{d}}$ & 4.75 & 1.2 & 11.0 & 0.36 \\
\hline
\end{tabular}

* or ** not significantly different at $P<0.05$

${ }^{\mathrm{a}}$ [23]; ${ }^{\mathrm{b}}$ [12]; $\mathrm{SC}_{50}$ concentration of catechins required to give a $50 \%$ decrease in the signal intensity of $\mathrm{DPPH}^{-} \mathrm{radical}^{\mathrm{c}}{ }^{\mathrm{C}}$ [24], $\mathrm{IC}_{50} \mathrm{con}^{-}$ centration of catechins required to give a $50 \%$ decrease in the lipid peroxidation assay; ${ }^{\mathrm{d}}[14] ;{ }^{\mathrm{e}}[25]$ 
1.0-2.0 in the stomach, $\mathrm{pH}$ 5.7-6.5 in the duodenum, $\mathrm{pH}$ 5.5-7.0 in the colon, $\mathrm{pH} 5.9-6.8$ in jejunum, $\mathrm{pH} 6.8$ in esophagus, through $\mathrm{pH} 7.3-7.7$ in ileum, $\mathrm{pH} 7.4$ in blood and other body fluids to the $\mathrm{pH} 7.6-8.6$ in pancreas [15, 16], the effect of $\mathrm{pH}$ on the antioxidant properties of catechin epimers may be of biological relevance. Catechins posses a great number of hydroxyl groups in their structures, which could deprotonate at physiological $\mathrm{pH}$ values influencing their antioxidant activity. To get better insight into the effect of deprotonation on the TEAC antioxidant activity of catechin epimers, the pKa values for catechins were determined (Table 2). Table 2 also presents calculated relative $\mathrm{DE}$ of the most acidic hydroxyl groups in the catechin molecules. The DE values indicate that the preferential site of $\mathrm{OH}$ deprotonation in non-galloylated catechins (C, EC, GC, and EGC) is $\mathrm{C}^{\prime}-\mathrm{OH}$ and/or $\mathrm{C}^{\prime}-\mathrm{OH}$. Introduction of galloyl moiety to the catechin molecule results in the change of $\mathrm{OH}$ deprotonation site from $\mathrm{C}^{\prime}$ $\mathrm{OH}$ to $\mathrm{C4}^{\prime \prime}-\mathrm{OH}$ in EGCG. In contrast to our previous results [14], it is shown that the introduction of the galloyl moiety to $\mathrm{GC}$ molecule does not influence preferential site of $\mathrm{OH}$ deprotonation in GCG, which remains $\mathrm{C}^{\prime}-\mathrm{OH}$ and $\mathrm{C} 4^{\prime}-\mathrm{OH}$ (Table 2).

Moreover, from the plot of $\mathrm{pKa}_{1}$ values for all catechins studied so far versus the $\mathrm{DE}$ values of the most acidic $\mathrm{OH}$ group in the catechin molecules (Fig. 2), the quantitative structure-activity relationship (QSAR) for catechins was obtained with correlation coefficient $R=0.975$. This equation could be used for prediction of the $\mathrm{pKa}_{1}$ values of the compounds with the flavan-3-ol structure. From Fig. 2, it also follows that the additional $\mathrm{OH}$ group creating pyrogallol moiety in GC and EGC structures results in decrease in both the DE and $\mathrm{pKa}_{1}$ values in comparison with $\mathrm{DE}$ and $\mathrm{pKa}_{1}$ of $\mathrm{C}$ and $\mathrm{EC}$. Moreover, the introduction of the galloyl moiety to a catechin molecule, as it is in ECG, GCG, and EGCG, results in further decrease in DE and $\mathrm{pKa}_{1}$ values.

Figure 3 presents the $\mathrm{pH}$-dependent TEAC profiles of the catechin epimers under study. From the plots presented, it follows that the radical scavenging activity of catechin

Table 2 Literature, experimental, and theoretically predicted $\mathrm{pKa}$ values, calculated relative deprotonation energies (DE), TEAC values of neutral forms of catechins, bond dissociation energies (BDE) as well as ionization potentials (IP) for neutral (N) and monoanionic forms (A) of catechin epimers

\begin{tabular}{|c|c|c|c|c|c|c|c|c|}
\hline Catechins & PKa exp. & pKa*calc. & $\begin{array}{l}\mathrm{DE} \\
(\mathrm{kcal} / \mathrm{mol})\end{array}$ & $\begin{array}{l}\text { TEAC(N) }{ }^{\mathrm{dla}} \\
\mathrm{pH}=\mathrm{pKa}-2\end{array}$ & $\begin{array}{l}\text { BDE(N) } \\
(\mathrm{kcal} / \mathrm{mol})\end{array}$ & $\begin{array}{l}\mathrm{IP}(\mathrm{N}) \\
(\mathrm{kcal} / \mathrm{mol})\end{array}$ & $\begin{array}{l}\text { BDE(A) } \\
(\mathrm{kcal} / \mathrm{mol})\end{array}$ & $\begin{array}{l}\mathrm{IP}(\mathrm{A}) \\
(\mathrm{kcal} / \mathrm{mol})\end{array}$ \\
\hline Catechin $(\mathrm{C})$ & $\begin{array}{l}\mathrm{pKa}_{1} 8.64^{\mathrm{a}} 8.97(\mathrm{~B})^{\mathrm{b}} \\
8.68^{\mathrm{c}} \\
\mathrm{pKa}_{2} 9.41^{\mathrm{a}} 9.26(\mathrm{~A})^{\mathrm{b}} \\
9.70^{\mathrm{c}} \\
\mathrm{pKa}_{3} 11.26^{\mathrm{a}} 11.18 \\
(\mathrm{~A})^{\mathrm{b}} 11.50^{\mathrm{c}} \\
\mathrm{pKa}_{4} 13.26^{\mathrm{a}} 13.25 \\
(\mathrm{~B})^{\mathrm{b}}\end{array}$ & 8.64 & $\begin{array}{l}335.7\left(4^{\prime}\right)^{\mathrm{d}} \\
336.9\left(3^{\prime}\right)^{\mathrm{d}}\end{array}$ & 3.32 & $81.0\left(4^{\prime}\right)^{\mathrm{d}}$ & $171.0^{\mathrm{d}}$ & $\begin{array}{l}80.1(5)^{\mathrm{d}} \\
\left(\mathrm{C} 4^{\prime}-\mathrm{O}^{-}\right)\end{array}$ & $\begin{array}{l}60.4^{\mathrm{d}} \\
\left(\mathrm{C}^{\prime}-\mathrm{O}^{-}\right)\end{array}$ \\
\hline Epicatechin (EC) & $\begin{array}{l}\mathrm{pKa}_{1} 8.72^{\mathrm{a}} \\
\mathrm{pKa}_{2} 9.49^{\mathrm{a}} \\
\mathrm{pKa}_{3} 11.23^{\mathrm{a}} \\
\mathrm{pKa}_{4} 13.40^{\mathrm{a}}\end{array}$ & 8.69 & $\begin{array}{l}336.4\left(3^{\prime}\right)^{\mathrm{d}} \\
336.9\left(4^{\prime}\right)^{\mathrm{d}}\end{array}$ & 3.48 & $80.9\left(4^{\prime}\right)^{\mathrm{d}}$ & $168.7^{\mathrm{d}}$ & $\begin{array}{l}79.4(5)^{\mathrm{d}} \\
\left(\mathrm{C} 4^{\prime}-\mathrm{O}^{-}\right)\end{array}$ & $\begin{array}{l}59.1^{\mathrm{d}} \\
\left(\mathrm{C} 4^{\prime}-\mathrm{O}^{-}\right)\end{array}$ \\
\hline $\begin{array}{l}\text { Gallocatechin } \\
\quad(\mathrm{GC})\end{array}$ & $\mathrm{pKa}_{1} 8.41$ & 8.29 & $330.3\left(4^{\prime}\right)$ & 3.38 & $75.4\left(4^{\prime}\right)$ & 169.7 & $\begin{array}{l}77.8\left(3^{\prime}\right) \\
\left(\mathrm{C}^{\prime}-\mathrm{O}^{-}\right)\end{array}$ & $\begin{array}{l}60.3 \\
\left(\mathrm{C}^{\prime}-\mathrm{O}^{-}\right)\end{array}$ \\
\hline $\begin{array}{l}\text { Epigallocatechin } \\
\text { (EGC) }\end{array}$ & $\mathrm{pKa}_{1} 7.73^{\mathrm{d}}$ & 8.08 & $\begin{array}{l}327.2\left(4^{\prime}\right)^{\mathrm{d}} \\
331.4\left(3^{\prime}\right)^{\mathrm{d}}\end{array}$ & 2.80 & $71.7\left(4^{\prime}\right)^{\mathrm{d}}$ & $164.6^{\mathrm{d}}$ & $\begin{array}{l}77.5\left(3^{\prime}\right)^{\mathrm{d}} \\
\left(\mathrm{C} 4^{\prime}-\mathrm{O}^{-}\right)\end{array}$ & $\begin{array}{l}59.6^{\mathrm{d}} \\
\left(\mathrm{C} 4^{\prime}-\mathrm{O}^{-}\right)\end{array}$ \\
\hline $\begin{array}{l}\text { Gallocatechin } \\
\text { gallate (GCG) }\end{array}$ & $\mathrm{pKa}_{1} 7.65$ & 7.61 & $\begin{array}{l}320.2\left(3^{\prime}\right) \\
321.2\left(4^{\prime}\right)\end{array}$ & 3.40 & $76.0\left(4^{\prime}\right)$ & 168.4 & $\begin{array}{l}76.3\left(4^{\prime}\right) \\
\left(C 3^{\prime}-\mathrm{O}^{-}\right)\end{array}$ & $\begin{array}{l}76.3 \\
\left(\mathrm{C} 3^{\prime}-\mathrm{O}^{-}\right)\end{array}$ \\
\hline $\begin{array}{l}\text { Epigallocatechin } \\
\text { gallate (EGCG) }\end{array}$ & $\begin{array}{l}\mathrm{pKa}_{1} 7.68^{\mathrm{d}} 7.75^{\mathrm{e}} \\
\mathrm{pKa}_{2} 8.0^{\mathrm{e}}\end{array}$ & 7.64 & $\begin{array}{l}320.6\left(3^{\prime}\right)^{\mathrm{d}} \\
321.6\left(4^{\prime \prime}\right)^{\mathrm{d}}\end{array}$ & 4.21 & $75.4\left(4^{\prime}\right)^{\mathrm{d}}$ & $166.7^{\mathrm{d}}$ & $\begin{array}{l}75.4\left(4^{\prime}\right)^{\mathrm{d}} \\
\left(\mathrm{C} 4^{\prime \prime}-\mathrm{O}^{-}\right)\end{array}$ & $\begin{array}{l}71.1^{\mathrm{d}} \\
\left(\mathrm{C} 4^{\prime \prime}-\mathrm{O}^{-}\right)\end{array}$ \\
\hline $\begin{array}{l}\text { Epicatechin gallate } \\
\text { (ECG) }\end{array}$ & $\mathrm{pKa}_{1} 7.76^{\mathrm{d}}$ & 7.72 & $\begin{array}{l}321.6\left(3^{\prime}\right)^{\mathrm{d}} \\
321.8\left(4^{\prime \prime}\right)^{\mathrm{d}}\end{array}$ & 4.86 & $77.7\left(4^{\prime \prime}\right)^{\mathrm{d}}$ & $166.8^{\mathrm{d}}$ & $\begin{array}{l}76.1\left(3^{\prime \prime}\right)^{\mathrm{d}} \\
\left(\mathrm{C} 4^{\prime \prime}-\mathrm{O}^{-}\right)\end{array}$ & $\begin{array}{l}70.9^{\mathrm{d}} \\
\left(\mathrm{C} 4^{\prime \prime}-\mathrm{O}^{-}\right)\end{array}$ \\
\hline
\end{tabular}

* Prediction of $\mathrm{pKa}$ was done using calculated DE and the QSAR of catechin epimers; the equation of the QSAR defined was $\mathrm{pKa}=0.0658 \mathrm{DE}-$ 13.4276; $R=0.975 ; P=0.00109$

${ }^{\mathrm{a}}$ [29]; ${ }^{\mathrm{b}}$ [30], capital letters in parentheses refer to the identification of A and B ring in catechin molecules, respectively; ${ }^{\mathrm{c}}$ [31]; ${ }^{\mathrm{d}}$ [14], for DE and BDE values, the numbers in parentheses refer to the position of the most easily deprotonated $\mathrm{OH}$ moiety; for BDE(A) and IP(A) values, the descriptors in parenthesis refer to the type of monoanion; ${ }^{\mathrm{e}}$ [32] 


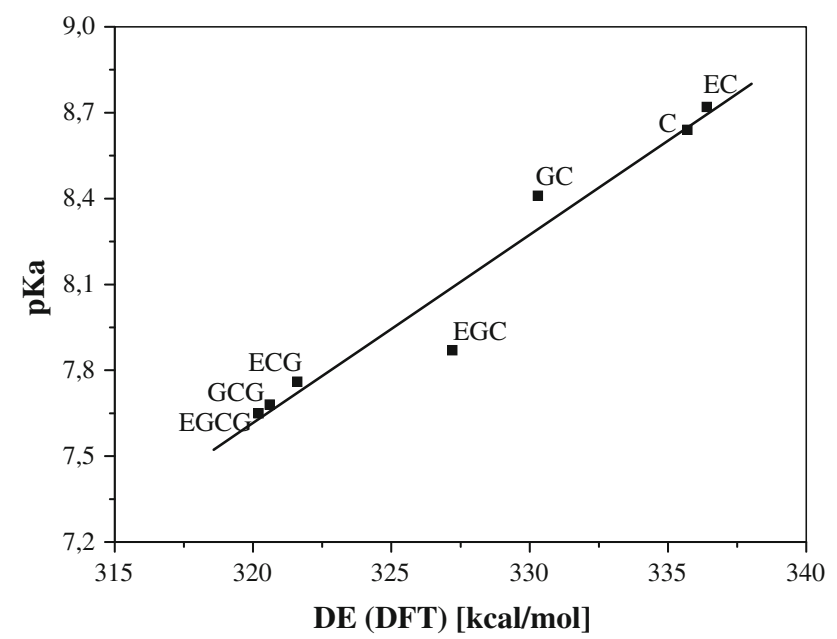

Fig. 2 Plot of the pKa $\mathrm{a}_{1}$ values of tea catechins (experimental and literature) against the calculated deprotonation energies (DE). The equation of the QSAR obtained is $\mathrm{pKa}_{1}=0.0658 \mathrm{DE}-13.4276$; $R=0.975$. The $\mathrm{pKa}_{1}$ value of catechin (C) was taken from Kennedy et al. [29]

epimers generally increases with an increase in $\mathrm{pH}$ of the surrounding medium. These results are in accordance with the previous study on the $\mathrm{pH}$-dependent radical scavenging capacity of some green tea catechins [14]. This increase for all the catechins studied occurs within physiological $\mathrm{pH}$ range.

Generally, pH-dependent TEAC antioxidant activity of $\mathrm{C}$ and EC is very similar (Fig. 3a). This leads to the conclusion that stereochemistry does not play a significant role in the antioxidant activity of these epimers. Comparison of the $\mathrm{pH}$-dependent TEAC profiles of the second pair of catechin epimers, that is, GC and EGC, indicates that the TEAC antioxidant activities of GC and EGC are very similar at $\mathrm{pH}$ range $2.0-7.0$ (Fig. 3b). At $\mathrm{pH}$ above 7.0 , the radical scavenging activity of GC clearly decreases, suggesting possible side reactions or decomposition. However, the linear correlation obtained for the plot of the absorbance at $734 \mathrm{~nm}$ measured after 6-min incubation of catechin with $\mathrm{ABTS}^{+}$radical cation versus the increasing concentrations of catechin allowed the assumption that the decrease in absorbance reflects especially the reaction between the $\mathrm{ABTS}^{+}$radical cation and catechin, and this reaction is not significantly affected by possible side reactions. Because the decrease in the TEAC values of GC appears only at alkaline $\mathrm{pH}$ range, it was concluded that the reason might be rather poor stability of $\mathrm{GC}$ at higher $\mathrm{pH}$ values than the difference in steric structure of catechins studied. To explain the decrease in the antioxidant activity of $\mathrm{GC}$ at $\mathrm{pH}$ above 7, additional experiment was performed to check the influence of alkaline $\mathrm{pH}$ of the medium on the GC stability. It was found that during 6-min incubation, $97 \%$ of GC is still present at $\mathrm{pH} 7.4$, whereas at $\mathrm{pH} 8.5$,
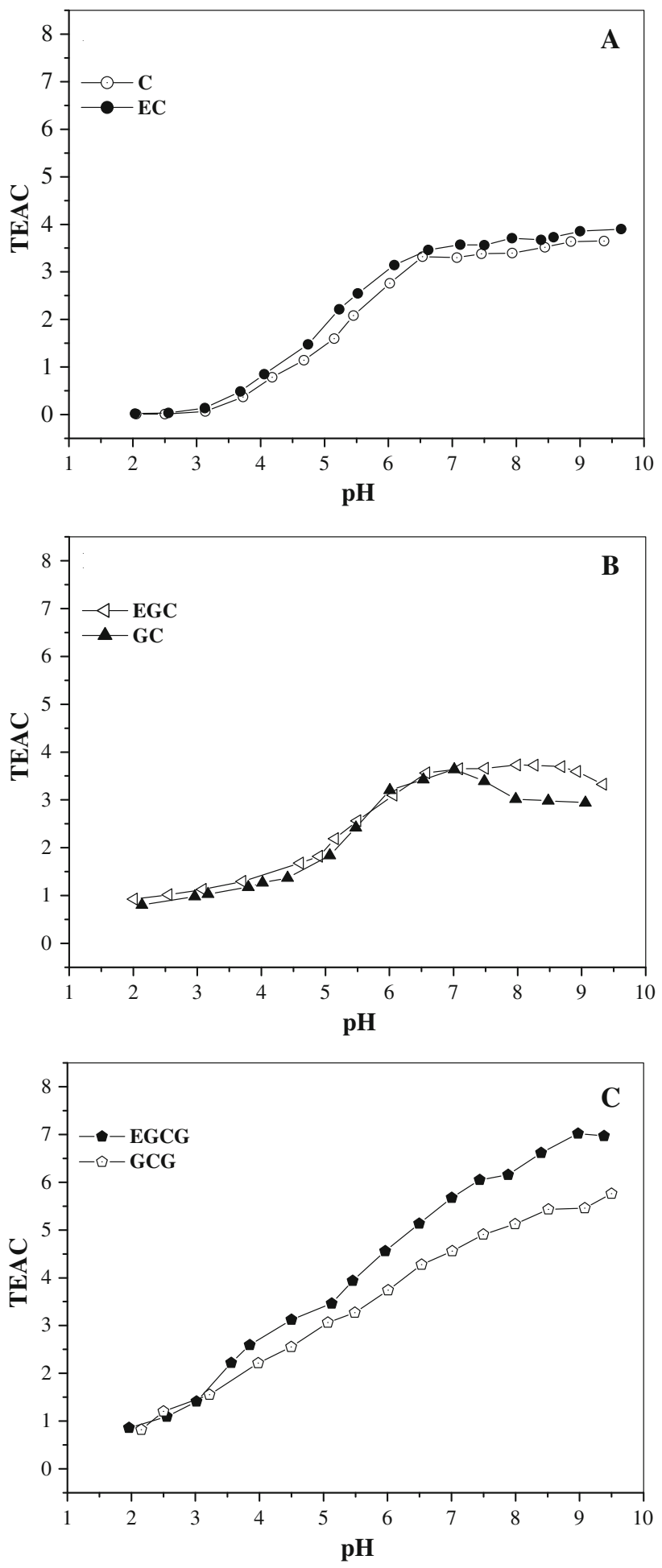

Fig. 3 pH-Dependent TEAC profiles of catechin epimers. a catechin (C) and epicatechin (EC); b gallocatechin (GC) and epigallocatechin (EGC); c gallocatechin gallate (GCG) and epigallocatechin gallate (EGCG)

the concentration of GC decreased up to $90 \%$. EGC concentration at $\mathrm{pH} 8.5$ was about $94.7 \%$. Literature data on the stability of EGC dissolved in buffers at the $\mathrm{pH}$ range 
from 3 to 11 [33] confirm our results showing that EGC is stable at alkaline $\mathrm{pH}$. It additionally supports the conclusion that the observed decrease in the TEAC antioxidant activity of GC comparing to its epimer EGC at $\mathrm{pH}$ above 7 is due to poor GC stability at alkaline medium.

Figure $3 \mathrm{c}$ presents the $\mathrm{pH}$-dependent TEAC profiles of the galloylated catechins, EGCG and GCG, which is the third pair of catechin epimers of this study. Figure $3 \mathrm{c}$ clearly reveals the influence of steric structure on the radical scavenging capacity of galloylated catechins at $\mathrm{pH}$ above 3.5, at which the TEAC values of EGCG are higher than those of GCG. Moreover, the differences in the TEAC values of these epimers increase with increasing $\mathrm{pH}$. The TEAC antioxidant activity of EGCG at $\mathrm{pH} 8.5$ is higher than the TEAC antioxidant activity of GCG for about $1.3 \mathrm{mM}$. Since the effect observed does not result from the instability or lower solubility of GCG at pH above 3.5 than its epi-form (about 98.6\% of GCG is still present at $\mathrm{pH}$ $8.5)$, alternatively the effect of deprotonation of $\mathrm{OH}$ group could play a role. However, the $\mathrm{pKa}_{1}$ values of both GCG and EGCG are nearly the same (7.68 and 7.65 for EGCG and GCG, respectively; Table 2); thus, the difference in the $\mathrm{pH}$-dependent TEAC profiles of both compounds could not be explained by the difference in $\mathrm{OH}$ group deprotonation with increasing $\mathrm{pH}$.

To explain the increase in the TEAC value of catechins with increasing $\mathrm{pH}$, that is, with deprotonation, theoretically calculated parameters, including $\mathrm{OH}$ BDE and IP for both the neutral $(\mathrm{N})$ and monoanionic (A) forms, were compared to the TEAC values of catechins tested. Table 2 presents the calculated data on the BDE and IP values, as well as the TEAC values for the neutral forms of the catechin molecules (calculated from the assumption that the molecule is in its neutral form at $\mathrm{pH}$ value corresponding to pKa value minus 2). From the comparison of the BDE values for the anionic and neutral forms of catechins, it could be concluded that BDE values do not change significantly upon deprotonation (Table 2) and this excludes hydrogen atom donation as the main mechanism of the radical scavenging action at higher $\mathrm{pH}$ values. In contrast, the parameter reflecting the ease of electron donation, that is, IP value, is much lower for the deprotonated forms of the catechins than for the neutral forms, reflecting easier electron donation upon deprotonation. Therefore, the increase in electron-donating ability upon deprotonation could explain the increase in the TEAC values of catechins with increasing $\mathrm{pH}$, and it can be concluded that electron donation is the dominant mechanism of antioxidant action of catechins upon their deprotonation. Thus, upon deprotonation, the radical scavenging capacity of tea catechins increases because electron donation by the anionic form, rather than hydrogen atom donation by the neutral form, becomes the mechanism of action. This is in agreement with the previous findings reported for hydroxyflavones, anthocyanins, and some catechins [14, 19, 34].

Furthermore, it was found that the IP(A) value calculated for monoanionic form of GCG is about $5.2 \mathrm{kcal} / \mathrm{mol}$ higher than IP(A) value of EGCG monoanion. Influence of stereochemistry on the radical scavenging properties of GCG and EGCG could be explained based on the theoretically predicted structures of the most stable forms of EGCG and GCG (Fig. 4). Deprotonation of EGCG leads to the most stable monoanion resulting from dissociation of $\mathrm{C} 4$ "- $\mathrm{OH}$ group in galloyl moiety (Table 2). The structure of EGCG monoanion is stabilized by a weak H-bonding between $\mathrm{C}^{\prime}$ - $\mathrm{OH}$ hydrogen atom and $\mathrm{C}^{\prime \prime}$-OH oxygen atom (Fig. 4a). Abstraction of one electron from this monoanion molecule results in relatively stable $\mathrm{C}^{\prime \prime}-\mathrm{O}$ phenoxy radical. The most stable GCG monoanion, as theoretically predicted, results from $\mathrm{C}^{\prime}-\mathrm{OH}$ group in pyrogallol moiety dissociation. This monoanion is stabilized by a strong $\mathrm{H}$-bonding between $\mathrm{C}^{\prime}-\mathrm{O}^{-}$oxygen atom and $\mathrm{C}^{\prime \prime}-\mathrm{OH}$ hydrogen atom (Fig. 4b). Abstraction of one electron from this monoanion molecule results in transient $\mathrm{C}^{\prime}-\mathrm{O}^{\prime}$ phenoxy radical, which is less stable than $\mathrm{C}^{\prime}-\mathrm{O}$ or $\mathrm{C}^{\prime \prime}-\mathrm{O}$. radicals. Based on the theoretically predicted steric structures of $\mathrm{C}^{\prime \prime}-\mathrm{O}$ and $\mathrm{C}^{\prime}-\mathrm{O}$ phenoxy radicals and calculated difference in IP of monoanionic forms of GCG and EGCG $(5.2 \mathrm{kcal} / \mathrm{mol})$, it was concluded that due to steric hindrance the IP(A) value of GCG is higher than that of EGCG, reflecting lower radical scavenging capacity of GCG in comparison with EGCG. Simultaneously, the lack of essential differences between the TEAC antioxidant activity of GCG and EGCG at pH range up to 3.5 could be explained by their similar IP(N) values (the difference accounts for only $1.7 \mathrm{kcal} / \mathrm{mol}$ ). Thus, due to stereochemistry, monoanion of GCG is worse electron donor than monoanion of EGCG, reflected by lower TEAC values of GCG than those of EGCG at $\mathrm{pH}$ above 3.5. Altogether, the results obtained reveal that biological activity of galloylated catechins will probably be influenced by their steric structure.

For other pairs of epimers (C/EC and GC/EGC), deprotonation of their molecules leads to the same most stable monoanion resulting from the $\mathrm{C}^{\prime}{ }^{\prime}-\mathrm{OH}$ group dissociation. This may explain similarity of $\operatorname{IP}(\mathrm{A})$ values of appropriate epimers (they differ only about $0.7-1.3 \mathrm{kcal} /$ mol), reflecting similar radical scavenging activity of $\mathrm{C}$ and $\mathrm{EC}$ as well as GC and EGC with increasing $\mathrm{pH}$ of the surrounding medium.

Additional results of the present study revealed the existence of an intermolecular antagonism of antioxidant active structural elements present in GCG. In contrast to our previous results [14] showing an additive effect of the two independent antioxidant active moieties, catechol or pyrogallol and galloyl moieties, present in ECG and/or 


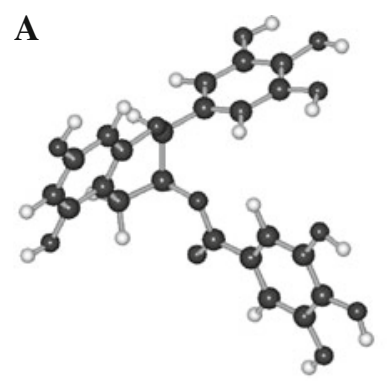

neutral form of EGCG

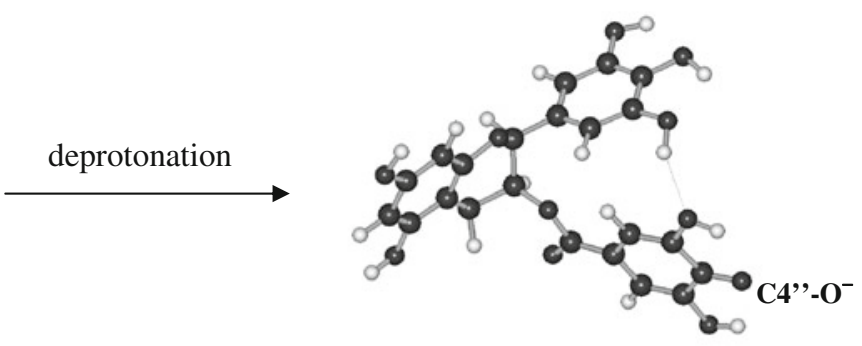

deprotonated form of EGCG

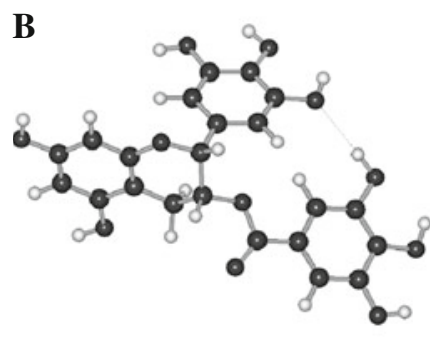

neutral form of GCG

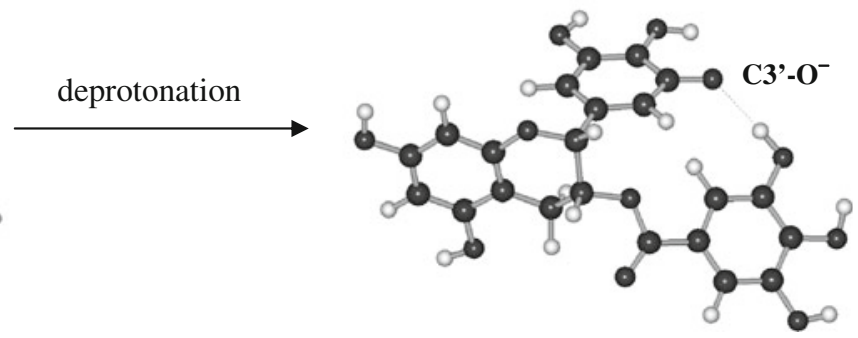

deprotonated form of GCG

Fig. 4 The structures of the most stable monoanions of (a) EGCG and (b) GCG

EGCG molecules responsible for high radical scavenging activity of these two catechins, this effect does not occur for GCG containing both galloyl and pyrogallol moieties. From the comparison of the $\mathrm{pH}$-dependent TEAC profile of GCG to the theoretically calculated curve of GCG obtained by summing up the $\mathrm{pH}$-dependent TEAC profiles of GC and methyl gallate (MG), the last representing galloyl moiety, it could be concluded that the TEAC values of this particular gallate ester could not be modeled by taking the sum of the TEAC values of GC and MG over the wide $\mathrm{pH}$ range tested. The TEAC values of GCG determined experimentally are lower over the $\mathrm{pH}$ range $3.5-8.5$ than theoretically calculated ones (Fig. 5). Based on the results of the present study, showing the influence of stereochemistry on radical scavenging activity of galloylated catechins, that is, GCG and EGCG, it was concluded that stereochemistry influences antagonistically the antioxidant action of pyrogallol and galloyl moieties in GCG molecule because the experimental TEAC values of GCG are lower over $\mathrm{pH}$ range above 3.5 from the theoretically calculated ones (Fig. 5). There are no literature experimental data on the possible influence of stereochemistry on $\mathrm{pH}$-dependent TEAC profile of GCG.

\section{Conclusions}

Based on the comparison of $\mathrm{pH}$-dependent radical scavenging activity of three pairs of catechin epimers, it was



Fig. 5 pH-Dependent TEAC profile of gallocatechin gallate (GCG) and the theoretical curve representing the sum of gallocatechin (GC) and methyl gallate (MG) TEAC curves

revealed that stereochemistry influences radical scavenging activity of galloylated catechins (GCG and EGCG). In case of non-galloylated catechins, $\mathrm{C}$ and $\mathrm{EC}$ as well as GC and EGC, steric structure has no essential influence on their $\mathrm{pH}$-dependent radical scavenging activities. The difference between radical scavenging activity of GCG and its epimer EGCG at pH higher than 3.5 may be explained based on theoretically predicted structures of GCG and EGCG and their calculated monoanion ionization potentials (IP(A)). It was concluded that due to steric hindrance in GCG 
molecule, the IP(A) value of GCG monoanion increases, reflecting lower radical scavenging capacity of GCG in comparison with EGCG.

Open Access This article is distributed under the terms of the Creative Commons Attribution License which permits any use, distribution, and reproduction in any medium, provided the original author(s) and the source are credited.

\section{References}

1. Arts IC, van de Putte B, Hollman PC (2000) Catechin contents of foods commonly consumed in The Netherlands. 1. Fruits, vegetables, staple foods, and processed foods. J Agric Food Chem 48: 1746-1751

2. Chun OK, Chung SJ, Song WO (2007) Estimated dietary flavonoid intake and major food sources of U.S. adults. J Nutr 137: 1244-1252

3. D'Archivio M, Filesi C, Di Benedetto R, Gargiulo R, Giovannini C, Masela R (2007) Polyphenols, dietary sources and bioavailability. Ann Ist Super Sanita 43:348-361

4. Arts IC, van de Putte B, Hollman PC (2000) Catechin contents of foods commonly consumed in The Netherlands. 2. Tea, wine, fruit juices, and chocolate milk. J Agric Food Chem 48:17521757

5. Beecher GR (2003) Overview of dietary flavonoids: nomenclature, occurrence and intake. J Nutr 133:3248S-3254S

6. Barbosa DS (2007) Green tea polyphenolic compounds and human health. Journal für Verbraucherschutz und Lebensmittelsicherheit 2:407-413

7. Cabrera C, Artach R, Jimenez R (2006) Beneficial effects of green tea-a review. J Am Coll Nutr 25:79-99

8. Cooper R, Morré J, Morré D (2005) Medicinal benefits of green tea: part I. Review of noncancer health benefits. J Altern Complement Med 5:521-528

9. Cooper R, Morré J, Morré D (2005) Medicinal benefits of green tea: part II. Review of anticancer properties. J Altern Complement Med 11:639-652

10. Kofink M, Papagiannopoulos M, Galensa R (2007) (-)-Catechin in cocoa and chocolate: occurrence and analysis of an atypical flavan-3-ol enantiomer. Molecules 12:1274-1288

11. Guo Q, Zhao B, Shen S, Hou J, Hu J, Xin W (1999) ESR study on the structure-antioxidant activity relationship of tea catechins and their epimers. Biochim Biophys Acta 1427:13-23

12. Nanjo F, Goto K, Seto R, Suzuki M, Sakai M, Hara Y (1996) Scavenging effects of tea catechins and their derivatives on 1,1-diphenyl-2-picrylhydrazyl radical. Free Radic Biol Med 21:895-902

13. Xu JZ, Yeung SVY, Chang Q, Huang Y, Chen Z-Y (2004) Comparison of antioxidant activity and bioavailability of tea epicatechins with their epimers. Br J Nutr 91:873-881

14. Muzolf M, Szymusiak H, Gliszczyńska-Świgło A, Rietjens IMCM, Tyrakowska B (2008) pH-dependent radical scavenging capacity of green tea catechins. J Agric Food Chem 56:816-823

15. Haeberlin B, Friend DR (2000) In: Friend DR (ed) Oral colonspecific drug delivery. CRC Press, Boca Raton

16. Rubinstein A (2007) In: Touitou E, Barry BW (eds) Enhancement in drug delivery. CRC Press, Boca Raton
17. Miller NJ, Rice-Evans C, Davis MJ, Gopinathan V, Milner A (1993) A novel method for measuring antioxidant capacity and its application to monitoring the antioxidant status in premature neonates. Clin Sci 84:407-412

18. Tyrakowska B, Soffers AEMF, Szymusiak H, Boeren S, Boersma MG, Lemańska K, Vervoort J, Rietjens IMCM (1999) TEAC antioxidant activity of 4-hydroxybenzoates. Free Radic Biol Med 27:1427-1436

19. Lemańska K, Szymusiak H, Tyrakowska B, Zieliński R, Soffers AEMF, Rietjens IMCM (2001) The influence of $\mathrm{pH}$ on the antioxidant properties and the mechanism of antioxidant action of hydroxyflavones. Free Radic Biol Med 31:869-881

20. Gliszczyńska-Świgło A, Muzolf M (2007) pH-Dependent radical scavenging activity of folates. J Agric Food Chem 55:8237-8242

21. Sauerwald N, Schwenk M, Polster J, Bengsch E (1998) Spectrometric $\mathrm{pKa}$ determination of daphnetin, chlorogenic acid and quercetin. Zeitschrift für Naturforschung B. J Chem Sci 53: 315-321

22. Frei B, Higdon JV (2003) Antioxidant activity of tea polyphenols in vivo: evidence from animal studies. J Nutr 133:3275S-3284S

23. Rice-Evans CA, Miller NJ, Paganga G (1996) Structure-antioxidant activity relationships of flavonoids and phenolic acids. Free Radic Biol Med 20:933-956

24. Yang B, Kotani A, Aral K, Kusu F (2001) Estimation of the antioxidant activities of flavonoids from their oxidation potentials. Anal Sci 17:599-604

25. Unno T, Yayabe F, Hayakawa T, Tsuge H (2002) Electron spin resonance spectroscopic evaluation of scavenging activity of tea catechins on superoxide radicals generated by a phenazine methosulfate and NADH system. Food Chem 79:259-265

26. Miura Y, Chiba T, Miura S, Tomita I, Umegaki K, Ikeda M, Tomita T (2000) Green tea polyphenols (flavan 3-ols) prevent oxidative modification of low density lipoproteins: an ex vivo studies in humans. J Nutr Biochem 11:216-222

27. Muzolf-Panek M, Gliszczyńska-Świgło A, de Haan L, Aarts JMMJG, Szymusiak H, Vervoort JM, Tyrakowska B, Rietjens IMCM (2008) Role of catechin quinones in the induction of EpREmediated gene expression. Chem Res Toxicol 21:2352-2360

28. Simos Y, Karkabounas S, Verginadis I, Charalampidis P, Filiou D, Charalabopoulos K, Zioris I, Kalfakakou V, Evangellou A (2011) Intra-peritoneal application of catechins and EGCG as in vivo inhibitors of ozone-induced oxidative stress. Phytomedicine 18:579-585

29. Kennedy JA, Munro MHG, Powell HKJ, Porter LJ, Yeap Foo L (1984) The protonation reactions of catechin, epicatechin and related compounds. Aust J Chem 37:885-892

30. Slabbert NP (1977) Ionization potential of flavanols and dihydroflavonols. Tetrahedron 33:821-824

31. Herrero-Martinez JM, Sanmartin M, Roses M, Bosch E, Rafols C (2005) Determination of dissociation constants of flavonoids by capillary electrophoresis. Electrophoresis 28:1886-1895

32. Jovanovic SV, Har Y, Steenke S, Simic MG (1995) Antioxidant potential of gallocatechins. A pulse radiolysis and laser photolysis study. J Am Chem Soc 117:9881-9888

33. Friedman M, Jürgens HS (2002) Effect of $\mathrm{pH}$ on the solubility of plant phenolic compounds. J Agric Food Chem 48:2101-2110

34. Borkowski T, Szymusiak H, Gliszczyńska-Świgło A, Rietjens IMCM, Tyrakowska B (2005) Radical scavenging capacity of wine anthocyanins is strongly $\mathrm{pH}$-dependent. J Agric Food Chem 53:5526-5534 